\title{
A SINTAXE DO SUJEITO E O LIVRO DIDÁTICO
}

Gabriele Damin de Souza ${ }^{1}$

Sandra Quarezemin ${ }^{2}$

Resumo: O objetivo deste trabalho é investigar a sintaxe do sujeito e o preenchimento da posição pré-verbal em alguns livros didáticos. Para tanto, analisamos três livros didáticos do tipo 'manual do professor'. A nossa hipótese é a de que o material distribuído aos alunos e professores no ensino básico, tido como input da modalidade escrita da língua, prende-se ao que é canônico no que toca à posição de sujeito, ignorando as inovações na gramática do português brasileiro (PB). Partindo das contribuições da Teoria Gerativa sobre a sintaxe do sujeito, investigamos como o material usado no ensino básico apresenta o preenchimento dessa posição aos estudantes. Foi realizada uma revisão da literatura sobre o Parâmetro do Sujeito Nulo e sobre como a marcação paramétrica ocorre no PB, levando em conta os seguintes aspectos: as contribuições acerca da aquisição e aprendizagem de línguas, os conhecimentos implícito e explícito dos alunos e o input escrito da língua.

Palavras-chave: Teoria gerativa. Sintaxe do sujeito. Ensino de Gramática. Livro didático.

\section{THE SYNTAX OF THE SUBJECT AND THE TEXTBOOK}

\begin{abstract}
The aim of this paper is to investigate the syntax of the subject and the filling of the pre-verbal position in some textbooks. We analyzed three textbooks of the type 'teacher's guides'. Our hypothesis is that the material distributed to students and teachers in basic education, taken as an input to the written modality of the language, is linked to what is canonical with regard to the position of subject, ignoring the innovations in the grammar of Brazilian Portuguese (BP). Through contributions of the Generative Theory on the syntax of the subject, we investigate how the textbook used in basic education presents to students the filling of subject position. We conducted a literature review about the Null Subject Parameter and about how the parametric marking occurs in BP, taking into account the following aspects: the contributions about language acquisition and learning, the implicit and explicit knowledge of the students and the written language input.
\end{abstract}

Keywords: Generative theory. Syntax of subject. Grammar teaching. Textbook.

\section{INTRODUÇÃO}

Ao encarar a língua como um fenômeno natural, percebe-se que o ensino de língua portuguesa na educação básica, pautado principalmente na Gramática Tradicional, não atende

\footnotetext{
${ }^{1}$ Universidade Federal de Santa Catarina - UFSC, Florianópolis - Santa Catarina, Brasil. Graduanda em Letras Português UFSC e Bolsista PIBIC/CNPq. ORCID <http://orcid.org/0000-0002-7405-412X>. E-mail: gabrieledsouza@outlook.com.

${ }_{2}^{2}$ Universidade Federal de Santa Catarina - UFSC. Doutora em Linguística pelo Programa de Pós-Graduação em Linguística da UFSC. Docente do Programa de Pós-Graduação em Linguística e do Departamento de Língua e Literatura Vernáculas da UFSC. Pesquisadora PQ-CNPq. ORCID <http://orcid.org/0000-0002-8570-5389>. Email: sandra@cce.ufsc.br.
} 


\section{Linguagens - Revista de Letras, Artes e Comunicação - ISSN 1981- 9943 \\ Blumenau, v. 15, n. 1, p. 052-073, jan./abr. 2021. \\ DOI: http://dx.doi.org/10.7867/1981-9943.2021v15n1p052-073}

a esse pressuposto e apresenta aos estudantes regras que "regem" o "bem falar/escrever" e que devem ser memorizadas, eliminando das aulas de gramática uma reflexão sobre o sistema linguístico do português brasileiro (PB). Como apontam Basso e Pires de Oliveira (2012, p. 16) "[...] o sistema de educação no Brasil era baseado em decorar coisas, em saber respostas corretas sem saber o que elas significam".

De acordo com Costa et al. (2011, p.30) “[...] o trabalho sobre o Conhecimento Explícito pressupõe que se explore o conjunto de intuições e conhecimentos adquiridos de forma não consciente pelos falantes". Uma boa maneira de colocar em prática esse preceito seria modificar o caráter tradicional das aulas de língua portuguesa, adotando uma visão científica da língua, alunos e professores formulando juntos hipóteses acerca de fenômenos observados no cotidiano de fala dos próprios estudantes. A partir desse movimento, os alunos poderiam pensar e compreender as regras gramaticais que envolvem o Português Brasileiro, além de, simplesmente, decorá-las ou reproduzi-las mecanicamente (PIRES DE OLIVEIRA; QUAREZEMIN, 2016).

Seguindo os preceitos da gramática gerativa, é preciso considerar que o aluno chega às aulas de português com um conhecimento implícito sobre sua língua materna, sendo papel do professor tornar explícito esse conhecimento, colocando o aluno no papel de "cientista" e fazendo da língua portuguesa um objeto de estudo. O conteúdo gramatical pode ser explorado pelos alunos como se estivessem em um laboratório de física ou química, por exemplo, seguindo as etapas do método científico (a observação, a formulação de hipóteses, a verificação, a confirmação ou refutação, a conclusão).

Tendo esse pano de fundo, este trabalho ${ }^{3}$ tem como objetivo verificar como o preenchimento da posição pré-verbal aparece para os estudantes na modalidade escrita da língua - presente nos materiais didáticos usados na escola, em especial no livro didático. Este tipo de material é tido como o input ${ }^{4}$ da língua escrita para os alunos - por alguns considerada como a aquisição de uma segunda língua (AGUIAR; VICENTE, 2017). A hipótese deste estudo é a de que o livro didático prioriza as formas canônicas da escrita do $\mathrm{PB}$, não apresentando aos alunos que o utilizam dados de "novos sujeitos", observados na fala cotidiana e que vem ocorrendo com mais frequência no PB.

\footnotetext{
${ }^{3}$ Este trabalho apresenta parte da pesquisa desenvolvida no Programa de Iniciação Científica da UFSC, realizada pela primeira autora, sob a orientação da professora Sandra Quarezemin. Agradecemos aos dois pareceristas pelos valiosos comentários e sugestões para a melhoria do texto. Os erros que permanecem são de nossa responsabilidade.

${ }^{4}$ Define-se por input “[...] tudo o que ouvimos em nossa língua materna em nossa fase de aquisição, como para o que ouvimos ou lemos após essa fase em nossa língua ou quando estamos aprendendo uma segunda língua" (SANTOS, 2013, p. 52).
} 


\section{Linguagens - Revista de Letras, Artes e Comunicação - ISSN 1981- 9943 \\ Blumenau, v. 15, n. 1, p. 052-073, jan./abr. 2021. \\ DOI: http://dx.doi.org/10.7867/1981-9943.2021v15n1p052-073}

O presente trabalho está dividido em dois momentos: primeiramente, foi realizada uma revisão bibliográfica, a fim de compreender o Parâmetro do Sujeito Nulo e a sintaxe do sujeito no PB; em um segundo momento, a fim de verificar a validade ou não da hipótese, foi realizada uma análise em alguns livros didáticos utilizados nos anos finais do Ensino Fundamental, mais precisamente, nos sétimos, oitavos e nonos anos.

Este artigo está organizado da seguinte forma: na primeira seção, apresentamos um breve panorama da sintaxe do sujeito, focando principalmente no Parâmetro do Sujeito Nulo; na seção seguinte, mostramos algumas construções com diferentes tipos de sintagmas em posição de sujeito, considerados por alguns autores como 'sujeitos inovadores' do PB (NEGRÃO; VIOTTI, 2014); em seguida, tecemos algumas considerações sobre o ensino de língua portuguesa; na última seção, apresentamos uma discussão sobre o preenchimento da posição pré-verbal nos livros didáticos; encerramos o texto com as considerações finais.

\section{A SINTAXE DO SUJEITO NO PORTUGUÊS BRASILEIRO}

A sintaxe do sujeito no PB apresenta um movimento de mudança: já considerada uma língua de sujeito nulo (pro-drop), como o Português Europeu (PE) e o italiano, por exemplo, ao longo do tempo, passou a apresentar características de línguas em que o preenchimento do sujeito é obrigatório, como ocorre no inglês e no francês. Atualmente, considerada uma língua de sujeito nulo parcial. Por isso, ao se comparar as duas línguas, PB e PE, pode-se observar diferenças como as explicitadas em (1):

(1) a. [Minha esposa] trabalha na Embratel. Elai ganha bem, mas eu acho que elai devia ganhar mais porque ela $a_{i}$ merece. $(\mathrm{PB})$

b. Ele $\mathbf{i}$ quer pescar tudo; $\emptyset_{\mathbf{i}}$ quer sempre arranjar umas taças. E $\emptyset_{\mathbf{i}}$ tem tido sorte com isso, porque $\emptyset_{\mathrm{i}}$ já teve três (taças) e eu inda só tive uma, que foi nesse concurso. (PE)

(KATO; DUARTE, 2014, p. 2)

De acordo com os pressupostos da Teoria Gerativa, e seguindo o que fundamenta o modelo de Princípios e Parâmetros (CHOMSKY, 1981), entende-se, de maneira geral, que há princípios universais, isto é, comum a todas as línguas, e parâmetros com valores binários, tendo a criança que escolher o valor que um certo parâmetro deve tomar. Essa escolha se dá a partir do input (os dados linguísticos de uma língua particular). 


\section{Linguagens - Revista de Letras, Artes e Comunicação - ISSN 1981- 9943 \\ Blumenau, v. 15, n. 1, p. 052-073, jan./abr. 2021. \\ DOI: http://dx.doi.org/10.7867/1981-9943.2021v15n1p052-073}

Logo, o Princípio de que toda sentença finita possui um sujeito (Princípio de Projeção Estendido - EPP), e que esse sujeito pode ou não ser foneticamente realizado, leva ao Parâmetro do Sujeito Nulo (CHOMSKY, 1981; RIZZI, 1986), que será marcado positivamente em línguas em que é preferível não realizar esse sujeito e negativamente em línguas em que o preenchimento dessa posição é obrigatório. Ratifica-se o que foi exposto, com base no que aponta Raposo (1992, p. 54-55),

[...] [o modelo de Princípios e Parâmetros é constituído por] princípios rígidos, invariáveis e que qualquer gramática final terá de incorporar e em um sistema de princípios abertos, os parâmetros, que são delimitados durante a fase de aquisição através da fixação, ou marcação, de valores para determinadas estruturas da língua, essa valoração é binária, ou seja, a criança, ao receber o input externo de sua língua, fixará um valor ou negativo ou positivo para a ocorrência da estrutura na sua gramática.

A partir desse modelo, é possível classificar as línguas como de sujeito nulo (ou línguas pro-drop), de sujeito preenchido (ou não pro-drop) ou como de sujeito nulo parcial (semi prodrop). Entre os fatores que favorecem o não preenchimento da posição de sujeito da sentença, Buthers e Duarte (2012, p. 65-66), fundamentados em Chomsky (1981, p. 240), destacam algumas propriedades das línguas pro-drop:

\section{i. Apresentam sujeitos pessoais foneticamente nulos:}

(2) pro Pensamos muito a este respeito.

\section{ii. Apresentam sujeitos expletivos foneticamente nulos:}

(3) pro Nevou muito esta noite.

\section{iii. Aceitam inversão livre do sujeito:}

(4) pro Jogaram a bola [os meninos].

\section{iv. Mantêm posição pós-verbal do objeto direto em orações passivas:}

(5) pro Foi convidado [um estudante] para a festa.

\section{v. Atribuem Caso Nominativo à direita:}

(6) Sou [eu] que estou aqui.

\section{vi. Possuem flexão de infinitivo pessoal:}

(7) Vai ser difícil [tu saíres mais cedo].

\section{vii. Ausência do efeito $<<$ that-t $t^{5}>>$ :}

\footnotetext{
${ }^{5}$ O filtro 'that-t' (CHOMSKY; LASNIK, 1977) proíbe a extração do sujeito de uma encaixada, a fim de evitar que o complementizador 'que' seja seguido pelo vestígio 't', como mostra a agramaticalidade de (ia):

(i) a. ${ }^{*} \mathrm{Who}_{\mathrm{i}}$ do you think [that $\mathbf{t}_{\mathrm{i}}$ read a book]?

b. Who do you think read a book?
} 


\section{Linguagens - Revista de Letras, Artes e Comunicação - ISSN 1981- 9943 \\ Blumenau, v. 15, n. 1, p. 052-073, jan./abr. 2021. \\ DOI: http://dx.doi.org/10.7867/1981-9943.2021v15n1p052-073}

(8) Quem (é que) tu pensas [que [t viu esse filme]]?

É importante destacar que a literatura gerativa associou por muito tempo o licenciamento do sujeito nulo a um paradigma verbal rico. $\mathrm{O}$ argumento era o de que as línguas que apresentassem esse paradigma abundante poderiam resgatar o sujeito da sentença por meio da morfologia do verbo (flexão). Huang (1984) mostrou que o chinês mesmo sendo considerado uma língua de sujeito nulo apresenta um sistema flexional simplificado. A partir de então, a concordância, como um elemento identificador das línguas de sujeito nulo, deixa de ser o fator determinante para a marcação do parâmetro pro-drop.

Inseridas nessa discussão, Kato e Duarte (2017) adaptam o quadro binário proposto por Kato e Negrão (2000), dividindo as línguas em três grupos: no grupo A, estão as línguas [+prodrop] que identificam o sujeito, pro, através da concordância pronominal (línguas de sujeito nulo prototípicas, como o italiano, o espanhol e o português europeu (PE); no grupo B, estão as línguas [+pro-drop] que identificam o sujeito a partir da correferência discursiva (línguas como o chinês, o japonês e o PB); e, no grupo C, estão as línguas [-pro-drop], ou seja, de sujeito preenchido (o inglês e o francês).

Figura 1. Classificação das línguas quanto ao preenchimento da posição sujeito

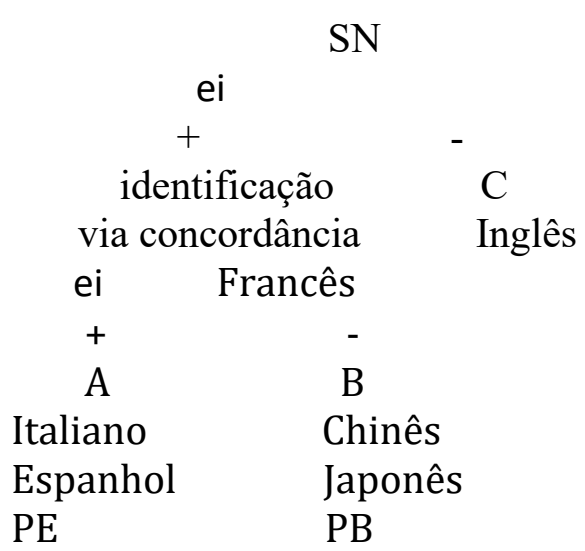

Fonte: Kato e Duarte (2017, p. 32)

O PB vem apresentando mudanças com relação à marcação paramétrica: enquanto algumas propriedades intrínsecas de línguas pro-drop podem ser observadas em textos escritos,

Isso ocorre nas línguas que têm sujeito obrigatório, como o inglês. Nas línguas de sujeito nulo, como o italiano, o filtro 'that-t' não se aplica (Rizzi, 1982), resultando em sentenças gramaticais, como em (ii):

(ii) $\mathrm{Chi}_{\mathrm{i}}$ credi [che $\mathbf{t}_{\mathbf{i}}$ partirà $]$ ? 


\section{Linguagens - Revista de Letras, Artes e Comunicação - ISSN 1981- 9943 \\ Blumenau, v. 15, n. 1, p. 052-073, jan./abr. 2021. \\ DOI: http://dx.doi.org/10.7867/1981-9943.2021v15n1p052-073}

a preferência pelo preenchimento da posição do sujeito na fala dos brasileiros também pode ser notada.

Duarte (1995) observa, a partir de dados da fala e da escrita de falantes do PB, que o paradigma flexional do $\mathrm{PB}$, antes considerado rico por apresentar seis flexões verbais distintas, sofreu mudanças e, atualmente, esse quadro reduziu a apenas três flexões, por consequência do desaparecimento gradual das formas pronominais de segunda pessoa - tu e vós, sendo substituídas pela forma "você" e pela substituição da forma pronominal de primeira pessoa do plural - nós -, sendo substituída pela forma "a gente". Como se pode observar no Quadro 1 abaixo, extraída do texto da autora.

Quadro 1. Paradigmas pronominal e flexional do PB

\begin{tabular}{|cllll|}
\hline Pess./N & Pronome & Paradigma & Paradigma & Paradigma \\
& & 1 & 2 & 3 \\
\hline $1^{\text {a }}$ sing. & Eu & am $\mathbf{~}$ & am $\mathbf{~}$ & am $\mathbf{~}$ \\
$2^{\text {a }}$ sing. & $\mathrm{Tu}$ & am a $\mathbf{~}$ & - & - \\
& Você & am a & am a & am a \\
$3^{\text {a }}$ sing. & Ele/Ela & am a & am a & am a \\
\hline $1^{\text {a }}$ plur. & Nós & am a mos & am a mos & - \\
& A gente & - & am a & am a \\
$2^{\text {a }}$ plur. & Vós & am a is & - & - \\
& Vocês & am a $\mathbf{~ m}$ & am a $\mathbf{~}$ & am a $\mathbf{~}$ \\
$3^{\text {a }}$ plur. & Eles/Elas & am a $\mathbf{~ m ~}$ & am a $\mathbf{~ m}$ & am a $\mathbf{~ m}$ \\
\hline
\end{tabular}

Fonte: Duarte (1995, p. 40)

De acordo com Duarte (1995), o enfraquecimento no paradigma flexional dos verbos do PB teria sido um dos fatores que impulsionaram as mudanças no que tange à marcação do Parâmetro do Sujeito Nulo. Pires de Oliveira e Quarezemin (2016, p. 134), destacam, contudo, que "o PB se coloca como uma língua intrigante quanto ao parâmetro pro-drop, pois, ainda que esteja perdendo a propriedade de sujeito nulo, mantém algumas características das línguas desse tipo".

O PB parece se comportar como uma língua de sujeito nulo parcial, aproximando-se, desse modo, das línguas pertencentes ao grupo C, na proposta de Kato e Duarte (2017), porém sem apresentar o expletivo lexical característico dessas línguas. Com relação ao tipo de sujeito nulo, Holmberg e Sheehan (2010) apresentam três condições nas quais o licenciamento do sujeito nulo pode ocorrer em línguas parcialmente pro-drop. Kato e Duarte (2017, p. 32) exemplificam tais condições com sentenças do PB, como verificamos em 10. 


\section{Linguagens - Revista de Letras, Artes e Comunicação - ISSN 1981- 9943 \\ Blumenau, v. 15, n. 1, p. 052-073, jan./abr. 2021. \\ DOI: http://dx.doi.org/10.7867/1981-9943.2021v15n1p052-073}
a. o sujeito nulo é não temático (=expletivo) (10a)
b. o sujeito nulo é um pronome genérico do tipo "one" do inglês (10b)
c. o sujeito nulo é controlado por um argumento numa sentença mais alta (10c)

(10) a. Øexpl está chovendo.

b. Øgen Não usa mais chapéu.

c. O Joãoi disse que $\boldsymbol{\emptyset}_{\mathbf{i}}$ fala bem espanhol.

Tendo em mente estas possibilidades de ocorrência de sujeito nulo no PB, junto do enfraquecimento do sistema flexional e do preenchimento da posição sujeito na fala dos brasileiros, na próxima seção, mostraremos como os usuários do PB vêm diversificando o tipo de sintagma que pode funcionar como sujeito.

\section{NOVOS SUJEITOS NA GRAMÁTICA DO PB}

Os falantes do PB usam diferentes tipos de sintagmas na posição pré-verbal. Destacamse, com base na literatura, as seguintes construções: (i) sujeito do tipo advérbios leves (BUTHERS; DUARTE, 2012); (ii) sujeito do tipo pronomes genéricos (LUNGUINHO; MEDEIROS JUNIOR, 2009; KATO; DUARTE, 2014; QUAREZEMIN; FUCHSBERGER, 2020), (iii) sujeito locativo (AVELAR, 2009; AVELAR; GALVES, 2011; AVELAR; CYRINO, 2008; REIS; QUAREZEMIN, 2019); (iv) preenchimento do sujeito em casos que a posição deveria não ser preenchida, sujeitos com verbos meteorológicos, por exemplo (BUTHERS; DUARTE, 2012; QUAREZEMIN, 2017); (v) sujeito com interpretação genitiva (PONTES, 1987; GALVES, 1998; NEGRÃO; VIOTTI, 2008; 2010; 2014).

No primeiro caso, Buthers e Duarte (2012) observam a emergência da ordem [XP V DP], sendo que o sintagma XP inicial não tem nenhuma informação semântica, comportandose como os advérbios leves. Por isso, construções como as dos exemplos em (11) são perfeitamente aceitas no PB contemporâneo.

(11) a. Lá vai a seleção brasileira para mais um jogo contra a Bolívia. (Fala espontânea)

b. Aqui constrói um país. (Fala espontânea)

c. Lá faz muitos shows grandes. (Fala espontânea)

(BUTHERS; DUARTE, 2012, p. 64) 


\section{Linguagens - Revista de Letras, Artes e Comunicação - ISSN 1981- 9943 \\ Blumenau, v. 15, n. 1, p. 052-073, jan./abr. 2021. \\ DOI: http://dx.doi.org/10.7867/1981-9943.2021v15n1p052-073}

No segundo caso, Kato e Duarte (2014) verificam que o desaparecimento do "se" indefinido desencadeia o preenchimento da posição de sujeito por pronomes genéricos e pelo nulo genérico, considerado resíduo de sujeito nulo.

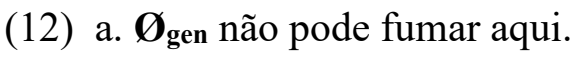

b. A gente não pode fumar aqui.

c. Você não pode fumar aqui.

(KATO; DUARTE, 2014, p. 9)

(13) Quando a pessoa vai lá não tem ninguém para atender.

(LUNGUINHO; MEDEIROS JUNIOR, 2009, p. 4)

(14) Aí tu vai na verdureira, compra um monte de coisa, chega em casa e vê que metade tá podre.

(QUAREZEMIN; FUCHSBERGER, 2020, p. 100)

Outra ocorrência muito produtiva na gramática do PB é o locativo preposicionado em posição de sujeito. Avelar (2009) apresenta casos de sentenças com alternância sintática, chamada de inversão locativa pelo autor, em que um sintagma locativo, preposicionado ou não, ocupa a posição pré-verbal. $\mathrm{O}$ autor compara dados do $\mathrm{PB}$ e do português europeu, que não permite esse tipo de construção, segundo Avelar (2009), e defende que tais sentenças ocorrem por conta do paradigma flexional empobrecido do PB.

(15) a. Aquela loja vende livro.

b. O meu DVD grava qualquer tipo de filme.

c. Esse restaurante serve todo tipo de salada.

(AVELAR, 2009, p. 232-233)

No quarto caso, figuram as sentenças em que a posição do sujeito deveria estar vazia, de acordo com o esperado pela gramática tradicional. Buthers e Duarte $(2012$, p. 83) ilustram a ocorrência desse tipo de construção quando o verbo meteorológico está presente, como em (16).

(16) a. A chuva tá chovendo forte. Ela chove sem parar. (corpus de fala de Itaúna)

b. A chuva tá chovendo grossa. (fala espontânea) 
c. Este dia choveu muito. (fala espontânea)

d. Aqui neva sempre. (fala espontânea)

(BUTHERS; DUARTE, 2012, p.83)

Ainda encontramos sentenças nas quais a posição do sujeito é preenchida por um sintagma do tipo genitivo. Nestas construções a relação de sentido semântico parte/todo entre dos sintagmas nominais licencia o preenchimento do sujeito.

(17) a. Quebrou o pé da mesa.

b. A mesa, quebrou o pé dela.

c. A mesa quebrou o pé.

(18) a. Furou o pneu do meu carro.

b. Meu carro, furou o pneu dele.

c. Meu carro furou o pneu.

(GALVES, 1998, p. 23)

Tendo em vista esse cenário de mudanças no paradigma flexional e de concordância dos verbos no PB, bem como os novos sintagmas que aparecem em posição de sujeito na língua, investigamos se, em âmbito escolar, os alunos são apresentados por meio do livro didático a essas construções recorrentes em seu cotidiano de fala. Desse modo, destaca-se que as ocorrências de sujeitos pronominais nulos e preenchidos estão no escopo deste trabalho.

\section{O ENSINO DE LÍNGUA PORTUGUESA}

Seguindo os pressupostos básicos da Teoria Gerativa, observamos que "o aluno de língua materna não aprende sua língua na escola: ele já chega à escola com uma gramática internalizada" (SANTOS, 2013, p. 27). Dessa forma, é preciso trabalhar, em âmbito escolar, a língua como um instrumento de desenvolvimento do conhecimento linguístico que o aluno já possui, o conhecimento implícito, a fim de tornar esse conhecimento explícito. Uma forma possível de trabalhar a consciência gramatical dos alunos, mobilizando a passagem do conhecimento implícito para o explícito, é através da experimentação científica (PIRES DE OLIVEIRA; QUAREZEMIN, 2016). Logo, 


\title{
Linguagens - Revista de Letras, Artes e Comunicação - ISSN 1981- 9943 \\ Blumenau, v. 15, n. 1, p. 052-073, jan./abr. 2021. \\ DOI: http://dx.doi.org/10.7867/1981-9943.2021v15n1p052-073
}

\begin{abstract}
As aulas de língua devem permitir ao aluno adotar uma perspectiva reflexiva e consciente da língua, devem suscitar o espírito de investigação/curiosidade e de interrogação face à linguagem que o aluno usa, devem desenvolver a aprendizagem das principais estruturas e dos mecanismos fundamentais da língua, devem, ainda, permitir a abordagem do tipo experimental (como nas ciências da natureza, por exemplo, na construção de puzzles, etc.) (XAVIER, 2012, p. 470).
\end{abstract}

De acordo com Lobato (2015), a escola vai propiciar a aquisição de novos estágios de conhecimento da língua. Nesse sentido, a autora se questiona sobre o que o aluno ainda pode adquirir, defendendo o ensino de gramática sob uma nova percepção, à luz da teoria gramatical moderna. Lobato $(2015$, p. 22) aponta que o 'grande desafio' é “formar professores capazes de renovar o ensino de língua". O professor deve aproveitar a aula de gramática para "tornar o conhecimento explícito da língua em um conjunto de saberes ao qual os alunos podem recorrer em contextos de uso diversificados, tornando-se usuários conscientes da sua língua." (QUAREZEMIN, 2017b, p. 70).

Cabe ainda uma reflexão sobre o próprio termo gramática. Como os professores definem e reconhecem o conceito de gramática? Muitos brasileiros associam à gramática um conjunto de regras do bem falar e do bem escrever. Se pensarmos no desenvolvimento das ciências da linguagem, essa visão sobre gramática é muito limitada. Avelar (2017, p. 16) afirma que

Infelizmente, a maior parte dos professores de português ainda baseia suas práticas didáticas em concepções que, além de não refletirem os avanços teóricos e empíricos dos estudos linguísticos contemporâneos, não respondem produtivamente às reais necessidades do aluno sobre o conhecimento e o uso da língua.

Em se tratando do ambiente escolar, ainda hoje o material mais utilizado pelo professor em sala de aula é o livro didático, que funciona como um suporte fundamental para o ensino, não somente de língua portuguesa. Lajolo (1996, p. 04) define os livros didáticos como sendo

[...] o livro que vai ser utilizado em aulas e cursos, que provavelmente foi escrito, editado, vendido e comprado, tendo em vista essa utilização escolar e sistemática. Sua importância aumenta ainda mais em países como o Brasil, onde uma precaríssima situação educacional faz com que ele acabe determinando conteúdos e condicionando estratégias de ensino, marcando, pois, de forma decisiva, o que se ensina e como se ensina o que se ensina. Assim, para ser considerado didático, um livro precisa ser usado, de forma sistemática, no ensino-aprendizagem de um determinado objeto do conhecimento humano, geralmente já consolidado como disciplina escolar.

Com base nisso e sabendo que o ensino de Língua Portuguesa no Brasil volta-se para o ensino e aprendizagem ${ }^{6}$ da língua escrita, é possível encarar esse material como principal input

\footnotetext{
${ }^{6}$ Distingue-se "aprendizagem da língua escrita" de "aquisição da língua", pois, com base em Santos (2013, p. 50), "[...] a fala, [é] resultado de um processo biológico, inato, que não necessita de instrução formal, é adquirida, e que a escrita, [é] resultado de um processo social de transmissão de conhecimentos por meio de instrução, é aprendida".
} 


\title{
Linguagens - Revista de Letras, Artes e Comunicação - ISSN 1981- 9943 \\ Blumenau, v. 15, n. 1, p. 052-073, jan./abr. 2021. \\ DOI: http://dx.doi.org/10.7867/1981-9943.2021v15n1p052-073
}

que o aluno receberá dessa modalidade do PB. Convém lembrar, contudo, que o livro didático, bem como uma gramática, não deve ser concebido como instrumento de aquisição da língua escrita (ainda que muitos pensem isso). Perini (2010, p. 17) descreve uma situação hipotética em que um autor de um livro de astronomia seria criticado por conta de o "seu texto não servir como orientação para a elaboração de horóscopos". O autor acrescenta que

\begin{abstract}
O objetivo de um livro de astronomia dirigido ao público geral é descrever (e em certa medida explicar) como funciona o cosmos: o sistema solar, as estrelas, os cometas, etc. Trata-se de um livro de informação científica, e se justifica em parte pela importância da ciência em nossos dias. [...]

Quando passamos ao campo da gramática, as coisas mudam: relativamente pouca gente espera estudar gramática como parte de sua formação científica. Em vez disso, esperam que o estudo de gramática lhes forneça meios de desenvolver seu desempenho na língua padrão, principalmente na escrita; para muitas pessoas, é isso o que justifica a presença dos estudos gramaticais na escola. (PERINI, 2010, p. 18)
\end{abstract}

O livro didático deve, portanto, proporcionar uma investigação da gramática que de alguma maneira resgate a autoconfiança linguística do aluno. Quarezemin (2017b) lembra da importância de buscar uma forma de trabalho que extinga ou, pelo menos, diminua o desinteresse do aluno pelas aulas de gramática. Se o professor insistir no ensino de gramática para 'escrever melhor', dificilmente despertará nos alunos a curiosidade, que é tão 'cara' em um processo de aprendizagem. Basso e Pires de Oliveira (2012, p. 27) afirmam que a linguística permite que as "aulas de português tenham um direcionamento totalmente diferente do que normalmente vemos, em particular, porque permite que o professor de português se liberte da prisão de ter como única função ensinar a escrever e a ler".

Nesse sentido, o aprendizado da língua escrita no ensino básico pode ser encarado como a aquisição de uma segunda língua (L2), como defendem Aguiar e Vicente (2017), com base em Kato (2005).

Diferentes fenômenos linguísticos fazem com que a língua padrão/culta escrita (e falada) deva ser encarada muito além da mera decodificação gráfica do vernáculo. Embora se tratando, convencionalmente, de uma mesma língua, valores paramétricos do PB falado são incompatíveis com determinadas propriedades gramaticais do PB padrão/culto (AGUIAR; VICENTE, 2017, p.95).

De acordo com Pires de Oliveira, Basso e Quarezemin (2013, p. 16-17), a perspectiva científica também é eficiente "no desenvolvimento da escrita e da leitura, porque permite que o aluno saiba manipular diferentes gramáticas, e aprenda que há diferentes línguas intermediárias, estágios na aprendizagem de uma outra língua”.

Diante desse quadro teórico, questionamo-nos como o livro didático vem abordando o conteúdo gramatical. Esse material permite a inclusão de todos os falantes ou está centrado apenas na variedade padrão do português? Já em 1995, Mário Perini, na Gramática Descritiva 


\section{Linguagens - Revista de Letras, Artes e Comunicação - ISSN 1981- 9943 \\ Blumenau, v. 15, n. 1, p. 052-073, jan./abr. 2021. \\ DOI: http://dx.doi.org/10.7867/1981-9943.2021v15n1p052-073}

do Português, propõe que as aulas de gramática permitem o ensino do raciocínio científico. Infelizmente, a visão reflexiva de língua ainda parece distante dos Parâmetros Curriculares Nacionais do Ensino Fundamental (PIRES DE OLIVEIRA; QUAREZEMIN, 2016).

Partindo dos pressupostos da Teoria Gerativista, que envolvem o conhecimento linguístico inato dos falantes e o aprendizado da língua escrita no ensino básico - que tem o livro didático como principal input dessa modalidade da língua - o objetivo é verificar se as novas formas de preenchimento da posição pré-verbal são encontradas no material didático. Nossa hipótese é a de que essas novas formas de preenchimento da posição pré-verbal ainda não foram incorporadas pelo material didático, que, em se tratando da escrita padrão da língua, há a preferência pela posição de sujeito pré-verbal nula indo ao encontro dos preceitos da gramática tradicional.

\section{$5 \quad$ A SINTAXE DO SUJEITO E O LIVRO DIDÁTICO}

A definição corrente de sujeito, que aparece em quase todas as gramáticas tradicionais, e, por conseguinte, no livro didático é a que se refere a sujeito como 'aquele sobre o qual se faz uma declaração'. Observe que tal definição não distingue o sintagma sujeito do tópico sentencial, ocasionando um problema para a análise sintática, como verificamos em (19).

(19) a. Carro manual eu não sei dirigir.

b. Os alunos o professor presenteou no fim do semestre.

Outras definições de sujeito que estão ancoradas na tradição normativa são: 'o sujeito concorda com o verbo' e 'o sujeito pratica a ação'. Não é difícil verificar que temos problemas com essas definições. Vejamos os exemplos abaixo:

(20) a. Acabou as férias.

b. O menino apanhou do irmão.

A concordância é sim uma propriedade muito importante na análise sintática do sujeito, mas os falantes produzem sentenças com sujeito posposto e, muitas vezes, sem concordância, esses fatos precisam ser levados em consideração pelo material didático apresentado aos alunos na educação básica. O ponto em questão não é o de encontrar a definição ideal ou substituir 


\section{Linguagens - Revista de Letras, Artes e Comunicação - ISSN 1981- 9943 \\ Blumenau, v. 15, n. 1, p. 052-073, jan./abr. 2021. \\ DOI: http://dx.doi.org/10.7867/1981-9943.2021v15n1p052-073}

uma definição que é imprópria por outra que seja mais apropriada (ou que dê conta do maior número de casos). É necessária uma nova forma de trabalhar a análise sintática dentro do livro didático. Uma análise que não leve em conta apenas a tradição normativa, que abra espaço para a variação linguística e para as ocorrências da língua em uso, focando mais na descrição (e menos na prescrição).

O livro didático adota a Nomenclatura Gramatical Brasileira (datada da década de 50), que tem como finalidade unificar as nomenclaturas empregadas nas escolas, com ênfase nas gramáticas. Para Perini (2010, p. 23), “a NGB parece mais um compromisso político, levando em conta inclusive os interesses imediatos de ensino, do que resultado de pesquisa linguística." O autor ainda destaca que "um sistema de descrição tem objetivos científicos, não primariamente pedagógicos." Segundo Avelar (2017, p. 46), as diferentes teorias “dedicadas à gramática das línguas naturais passaram a elaborar nomenclaturas mais sofisticadas, que têm por objetivo não apenas descrever determinada língua, mas também assegurar o poder explanatório de seus modelos."

A fim de investigar a sintaxe do sujeito no livro didático, analisamos os livros da coleção “Para Viver Juntos" (MARCHETTI et al., 2015), dedicada ao ensino de língua portuguesa. Esse material está fundamentado na concepção de linguagem interacionista, seguindo as propostas dos documentos nacionais para a educação (Base Nacional Comum Curricular BNCC) e trabalha com os conceitos de Competências e Habilidades. No manual do professor, os autores da coleção apresentam como eixos "a competência leitora, a resolução de problemas e a discussão de valores envolvidos no tema da convivência” (MARCHETTI et al., 2015, p. 293).

Um aspecto que chama atenção é o fato de os autores destacarem para os docentes a importância de tratar das variações do português, com o intuito de mostrar aos alunos a língua como ela é. Mas, a partir da leitura integral dos três livros didáticos selecionados - manuais do professor utilizados nos $7^{\circ}, 8^{\circ}$ e $9^{\circ}$ anos do ensino fundamental - constatamos que, em se tratando da sintaxe do sujeito, não aparecem no livro didático as construções tidas como inovadoras na gramática do português brasileiro (PB), aquelas mostradas na seção 3 deste trabalho.

\footnotetext{
${ }^{7}$ Por se tratar de uma pesquisa de iniciação científica, foram escolhidos apenas os livros didáticos dos anos escolares $7^{\circ}, 8^{\circ}$ e $9^{\circ}$ do ensino fundamental. De acordo com a professora da educação básica que assessorou a análise do material, nessas séries a sintaxe do sujeito ganha certo destaque por tratar da concordância verbal. Em termos metodológicos, os dados foram coletados a partir da leitura integral dos três livros realizada pela bolsista PIBIC. Quanto à organização dos dados, verifica-se, conforme será apresentado nesta seção, um distanciamento da variedade coloquial falada.
} 


\section{Linguagens - Revista de Letras, Artes e Comunicação - ISSN 1981- 9943 \\ Blumenau, v. 15, n. 1, p. 052-073, jan./abr. 2021. \\ DOI: http://dx.doi.org/10.7867/1981-9943.2021v15n1p052-073}

Se os autores do livro didático reconhecem a importância da variação linguística, por que não exploram a língua como ela é? Por que não foram encontrados registros da sintaxe do sujeito como os dados apresentados na seção 3 deste artigo? O livro didático está de fato cumprindo com o seu papel? Nosso intuito não é pré-julgar o livro didático, mas apontar para a necessidade de que o material também apresente espaço para os dados da língua em uso.

Nosso objetivo, além de verificar como a sintaxe do sujeito é tratada no material didático, é analisar a escrita dos autores do livro, a fim de investigar como é o input da modalidade escrita da língua que os alunos recebem no que se refere ao sujeito. Por isso, analisamos se a posição pré-verbal era preenchida por um sujeito realizado ou não.

Com relação à análise do livro utilizado no $7^{\circ}$ ano, observa-se que há uma preferência, tanto na escrita dos autores, quanto em outros gêneros textuais, pelo não preenchimento da posição pré-verbal por pronomes pessoais de primeira pessoa (eu e nós) e de terceira pessoa (elelela e eles/elas), algo já esperado na modalidade escrita da língua (KATO, 1986).

Este cenário foi verificado, por exemplo, no sétimo capítulo do livro, intitulado "Carta do leitor e carta de reclamação". O gênero textual carta traz como característica a pessoalidade, tem como tema a opinião pessoal do leitor, portanto, era esperado um uso maior da primeira pessoa do singular nos textos apresentados aos alunos pelos autores, como pode ser observado nos exemplos (21) e (22), que trazem excertos de cartas do leitor e de reclamação, respectivamente.

(21) Ø Estou chocada com a reportagem, principalmente a parte em que a Nasa analisa a passagem do sol em cada signo [...] (MARCHETTI, et al., 2015, p. 2016)

(22) [...] Ø Entro em contato com vocês porque até agora $\emptyset$ não recebi nenhum outro contato da bicicletaria. Ø Gostaria de ter alguma previsão direto da [nome da empresa], visto que o prazo de 30 dias é mais tempo do que eu tenho utilizado a bicicleta [...] (MARCHETTI, et al., 2015, p. 2016)

Também observamos uma preferência pelo preenchimento da posição pelos pronomes você(s) e a gente, mais comuns em contexto de fala. Essa constatação remete ao enfraquecimento do paradigma flexional e ao fato de que um paradigma flexional rico, pode influenciar, de certa forma, no licenciamento de sujeitos pré-verbais nulos. No exemplo (23), extraído do material analisado, pode-se perceber que a grande maioria das ocorrências de 


\section{Linguagens - Revista de Letras, Artes e Comunicação - ISSN 1981- 9943 \\ Blumenau, v. 15, n. 1, p. 052-073, jan./abr. 2021. \\ DOI: http://dx.doi.org/10.7867/1981-9943.2021v15n1p052-073}

preenchimento da posição de sujeito pré-verbal com o pronome você é decorrente de uma tentativa de construção de diálogo com os alunos.

(23) Os dois textos que você leu foram escritos com propósitos específicos. Em qual dos dois textos você pôde identificar mais explicitamente o uso de recursos que auxiliam a leitura? Por que você acha que isso ocorre? ((MARCHETTI, et al., 2015, p.171).

Na busca por uma aproximação com os estudantes, o autor preenche a posição do sujeito. A mesma situação é encontrada na análise do livro didático do $8^{\circ}$ ano. Vale acrescentar que, no caso do exemplo (24) - extraído de uma peça teatral - o preenchimento da posição préverbal ocorre com o pronome você, enquanto os casos em que a posição está nula, o sujeito recuperado através da concordância verbal é o de segunda pessoa do singular, o que indicaria um "desvio de concordância".

(24) [...] PROFESSOR - Não antes de eu ler o que está escrito no livro. Espero ao menos que o português esteja correto. (Lendo) "Você meu amado e indolatrado mestre, és responçável por aquela que cativas." Três erros, um de concordância - "você és"; "indolatrado"; e responsável com ç? Desde quando?

Ao longo da leitura do material, verificamos que as ocorrências do pronome pessoal nós são preferencialmente nulas, enquanto as ocorrências de a gente são, em sua maioria, preenchidas, como observado no trecho retirado do texto que compõe a primeira leitura do capítulo: "Diário de Zlata". No trecho, as ocorrências da forma pronominal de primeira pessoa singular também são nulas.

(25) [...] Nunca mais $\boldsymbol{\emptyset}$ falei de mim para você, $\boldsymbol{\emptyset}$ falo de guerra, de morte, de ferimentos, de granadas, de tristeza e de sofrimento. Quase todos os meus amigos partiram. Mas mesmo que eles estivessem aqui, será que a gente ia conseguir se ver? O telefone não funciona, e Ø não íamos poder nem conversar [...] (MARCHETTI, et al., 2015, p.80).

A partir da análise dos dados, verificamos que o número de ocorrências do pronome você na posição de sujeito é superior ao número de ocorrências da forma pronominal $t u$, enquanto o número de ocorrências de sujeito não preenchido pelo pronome de primeira pessoa 


\title{
Linguagens - Revista de Letras, Artes e Comunicação - ISSN 1981- 9943 \\ Blumenau, v. 15, n. 1, p. 052-073, jan./abr. 2021. \\ DOI: http://dx.doi.org/10.7867/1981-9943.2021v15n1p052-073
}

do plural nós é superior ao número total de ocorrências do pronome a gente. Ou seja, se a posição estiver vazia, a forma pronominal correspondente é nós ao invés de a gente. O vazio se mantém com a primeira pessoa plural porque ainda nos restou uma marcação de concordância.

Acerca disso, destaca-se o que aponta Duarte (1995, p. 14):

\begin{abstract}
passamos por um período de mudanças profundas no que diz respeito ao licenciamento e a identificação do sujeito nulo de referência definida paralelamente à redução ocorrida no quadro pronominal, que provocou uma simplificação no nosso paradigma flexional. Embora não se possa dizer que perdemos a possibilidade de omitir o sujeito, observa-se clara preferência pelo uso da forma pronominal plena.
\end{abstract}

Partindo para a análise do livro utilizado no $9^{\circ}$ ano, percebe-se que os dados obtidos mantêm as ocorrências observadas nos outros dois livros. Há mais casos de primeira pessoa gramatical (eu e nós) nulos, quase nenhuma ocorrência da segunda pessoa gramatical $t u$ em posição pré-verbal e a preferência do preenchimento nos casos em que é utilizado o pronome você em concordância com o verbo, principalmente nos campos destinados ao "diálogo" dos autores com os estudantes.

Neste material, destaca-se o quinto capítulo, que traz como leituras centrais trechos de uma peça teatral e de um roteiro de filme, cada trecho corresponde a épocas distintas, há um distanciamento temporal entre eles. É interessante comparar sentenças dos dois excertos para observar movimentos de mudanças na escrita dos dois gêneros, semelhantes em se tratando da sua estrutura e que se aproximam, de certa forma, da fala cotidiana, mas que foram redigidos em períodos distintos. O exemplo (26) foi extraído da peça "O Judas em sábado de aleluia", de Luís Carlos Martins Pena, já o exemplo (27), do roteiro do filme "Meu tio matou um cara", escrito por Jorge Furtado.

(26) [...] CAPITÃO, chegando-se para ela - Desejei ver-te, e a fortuna ajudou-me. (Pegandolhe na mão:) Mas que tens? Estás receosa! Teu pai? (MARCHETTI, et al., 2015, p. 146).

(27) [...] Você podia ter ligado, eu fui dormir tarde. A gente ficou vendo um filme no sessenta e um. (MARCHETTI, et al., 2015, p. 160).

Comparando os dados, verifica-se na peça o uso de sujeito nulo referente aos pronomes $e u$ e $t u$, enquanto no roteiro a posição do sujeito é preenchida pelos pronomes você, a gente e $e u$. Também nos exemplos (28) e (29), extraídos da seção "Oralidade”, do oitavo capítulo do livro utilizado no $9^{\circ}$ ano, pode-se observar ocorrências de preenchimento do sujeito compatível com a modalidade falada da língua. 


\section{Linguagens - Revista de Letras, Artes e Comunicação - ISSN 1981- 9943 \\ Blumenau, v. 15, n. 1, p. 052-073, jan./abr. 2021. \\ DOI: http://dx.doi.org/10.7867/1981-9943.2021v15n1p052-073}

(28) Ø Estou honrado de estar aqui, na formatura de uma das melhores universidades do mundo. Que a verdade seja dita, eu nunca me formei na universidade. Isso é o mais perto que eu já cheguei de uma cerimônia de formatura. Hoje, eu gostaria de contar a vocês três histórias da minha vida. (MARCHETTI, et al., 2015, p. 270).

(29) [...] Ø Estou convencido de que a única coisa que me permitiu seguir adiante foi o meu amor pelo que fazia. Você tem que descobrir o que você ama. Isso é verdadeiro tanto para o seu trabalho quanto para com as pessoas que você ama. (MARCHETTI, et al., 2015, p. 270).

O recorrente preenchimento da posição sujeito pelos pronomes você(s) e a gente, substituindo a segunda pessoa do singular/plural e a primeira pessoa do plural, atesta um processo de mudança pelo qual o PB vem atravessando. Este aspecto é positivo, porque aproxima os estudantes de uma língua real, não baseada somente na prescrição. Mas, infelizmente, no geral, o material didático não reflete a 'real' sintaxe do sujeito no português brasileiro, além de não abrir espaço para uma reflexão linguística sobre os dados reais. Não identificamos nenhuma menção a qualquer tipo de construção 'inovadora', não há nenhum dado que mostre aos alunos a possibilidade de sintagmas de diferentes tipos ocuparem a posição do sujeito (como apresentado na seção 3).

A hipótese deste estudo se confirmou, pois verificamos que o livro didático oferecido aos alunos da educação básica segue o caráter normativo, priorizando uma análise tradicional do sujeito, sem refletir a variedade presente no PB no que se refere aos tipos de sintagmas que os falantes usam em posição de sujeito. Este estudo aponta para a necessidade de se repensar a elaboração do livro didático do PB com relação à análise sintática do sujeito. É primordial que o material didático mostre uma reflexão sobre o processo de mudança que o PB vem atravessando e que reflete diretamente na sua gramática. Isso apenas será feito quando o material didático abrir espaço para uma perspectiva reflexiva de língua, não prescritiva.

Também verificamos que a nomenclatura do livro didático não é a mais adequada. Avelar (2017, p. 53) aponta que

Boa parte dessa nomenclatura, elaborada na década de 50, não reflete critérios que priorizam a intuição dos falantes a respeito da língua, mesmo porque sua elaboração se deu em um período no qual os avanços da Linguística ainda não se faziam sentir com força entre os estudos gramaticais desenvolvidos no Brasil. A NGB é calcada em um modelo que procura normatizar o idioma, tendo como alvo uma gramática idealizada, distante da realidade linguística vivenciada pelos falantes. 


\section{Linguagens - Revista de Letras, Artes e Comunicação - ISSN 1981- 9943 \\ Blumenau, v. 15, n. 1, p. 052-073, jan./abr. 2021. \\ DOI: http://dx.doi.org/10.7867/1981-9943.2021v15n1p052-073}

Como observam Hochsprung e Zendron da Cunha (2019, p. 601), os livros didáticos seguem uma "perspectiva ainda muito normativa e sem embasamento científico, o que limita o professor em sala de aula, o qual não consegue, se seguir o livro como guia definitivo, trabalhar longe de uma perspectiva tradicional." Os autores não sugerem o abandono do livro didático, mas afirmam que

[...] o professor deve ter um olhar crítico para o seu conteúdo e, quando necessário, deve fazer as alterações necessárias para que seu uso seja mais produtivo. Além disso, cabe ao professor investir na elaboração de sequências didáticas e de materiais próprios que considerem um viés mais científico e, portanto, agucem a criatividade e o pensamento crítico dos estudantes. (HOCHSPRUNG; ZENDRON DA CUNHA, 2019, P. 602).

Nesse sentido, sugerimos fortemente que haja uma maior colaboração entre os linguistas e os professores da educação básica, a fim de que juntos possam explorar as nuances da língua, sem privilegiar um único ponto de vista. Segundo Lobato (2015, p. 51), “dessa colaboração deveriam surgir novos materiais escolares, levando em conta o uso da língua em diversas situações de comunicação."

Infelizmente, outro fator ignorado na elaboração do livro didático é "o fato de haver comunidades bilíngues no Brasil, onde o português entra como língua aprendida na escola (LOBATO, 2015, p. 51)." Neste caso, um falante do dialeto italiano como primeira língua, por exemplo, pode apresentar uma sintaxe que não corresponde à do português brasileiro em se tratando do preenchimento da posição pré-verbal de sujeito. Se o livro pelo menos apontar para essa realidade, o professor estará mais atento aos alunos bilíngues.

Não é finalidade da linguística oferecer ao ensino de língua portuguesa receitas prontas nem mesmo aplicações pedagógicas. O que a linguística pode oferecer é instrumentos de descrição e análise mais precisos, que ofereçam mais segurança ao professor de gramática. Dessa forma, o professor terá condições de refletir sobre a língua em funcionamento, enquanto os alunos conseguirão, a partir das aulas com mais reflexão linguística, depreender as regras que fundamentam a sua língua.

Nossa proposta, que não se restringe apenas à sintaxe do sujeito, ao aparecimento de formas inovadoras na posição de sujeito, é a de que o professor de gramática não se limite apenas ao conteúdo que está posto no livro didático, que vá além, trazendo para a sala de aula a reflexão sobre os dados da língua falada (em funcionamento). O professor pode montar um banco de dados com a turma, trabalhar a metodologia científica com base na atividade de coleta de dados, incentivar a observação dos alunos frente aos fatos linguísticos. O passo seguinte será elaborar um quadro descritivo do fenômeno em foco: os alunos estarão na posição dos linguistas, lançarão as hipóteses, enquanto o professor orientará todo o processo. A etapa final 


\section{Linguagens - Revista de Letras, Artes e Comunicação - ISSN 1981- 9943 \\ Blumenau, v. 15, n. 1, p. 052-073, jan./abr. 2021. \\ DOI: http://dx.doi.org/10.7867/1981-9943.2021v15n1p052-073}

consiste na análise dos dados. Nesta fase, o professor deve provocar uma reação da turma, a fim de que os alunos lancem possíveis explicações para os dados coletados. Não desconsideramos em momento algum que essa atividade só terá êxito se o professor tiver uma formação sólida, que o permita ser o mediador das etapas descritas na atividade de reflexão linguística.

\section{CONSIDERAÇÕES FINAIS}

O português brasileiro contemporâneo apresenta uma gramática 'mista' no que diz respeito à sintaxe do sujeito. Mista no sentido de que permite sujeito nulo na escrita e em contextos restritos de fala, e, ao mesmo tempo, apresenta uma preponderância pelo preenchimento da posição de sujeito na fala. Esse preenchimento é tão recorrente que propiciou o aparecimento de diferentes tipos de sintagmas em posição pré-verbal. Ocorre que, infelizmente, essa realidade 'linguística' ainda não aparece nos livros didáticos.

Observamos que os autores do livro didático privilegiam a gramática tradicional, mantendo a prescrição da língua. O material didático apresenta em maior número sentenças com a posição pré-verbal nula, desfavorecendo, consequentemente, o aparecimento de diferentes tipos de constituintes na posição de sujeito. Fato que vem sendo observado com frequência na modalidade falada do PB.

Apesar de o livro didático não acompanhar a inovação da gramática do PB no que tange à sintaxe do sujeito, foi possível observar, ao longo da análise realizada, o uso significativo das expressões a gente e você - principalmente nas tentativas de diálogo com os estudantes - o que é mais comum na fala cotidiana do que na modalidade escrita. Pode ser um indicativo de que os autores desses manuais aos poucos vão incorporando algumas mudanças da gramática do PB. De qualquer forma, faz-se necessária uma renovação do livro didático.

Não desconsideramos a importância do livro didático, mas defendemos que esse material não privilegie a língua escrita, a norma culta falada pelos falantes com um grau alto de instruções. O livro didático pode incorporar reflexões linguísticas amparadas na visão científica da língua, que valoriza o português brasileiro, a língua dos alunos. Esse conteúdo pode aparecer no material didático, não com o objetivo de formar linguistas ou gramáticos na educação básica, mas sim de proporcionar aos alunos o contato com a prática científica também no âmbito da gramática, nas aulas de língua portuguesa. Estamos certas de que esse 'novo olhar' para a 
gramática da língua vai gerar bons frutos! (DUARTE, 2008; COSTA et al., 2011; LARSON, 2010; HONDA; O’NEIL; PIPPIN, 2010; XAVIER, 2009; 2012).

\section{REFERÊNCIAS}

AGUIAR, A. C. N.; VICENTE, H. G. O lugar do input e dos conhecimentos implícito e explícito na aquisição de L2 e na aprendizagem da escrita do PB. Work. Pap. Linguíst., n.18, v.2, p. 93-110, Florianópolis, ago./dez., 2017.

AVELAR, J. O. de. Saberes gramaticais: formas, normas e sentidos no espaço escolar. São Paulo: Parábola, 2017.

AVELAR, J. O. de. Inversão locativa e sintaxe de concordância no português brasileiro. Matraga, [S.1.], v.16, n. 24, dez. 2009.

BASSO, R. M.; PIRES DE OLIVEIRA, R. Feynmann, a linguística e a curiosidade, revisitado. Matraga, Rio de Janeiro, v.19, n.30, jan./jun., 2012.

BUTHERS, C. M.; DUARTE, F. B. Português Brasileiro: uma língua de sujeito nulo ou de sujeito obrigatório. Diacrítica, Braga, v.26, n.1, p. 64-88, 2012.

CHOMSKY, N.; LASNIK, H. Filters and Control. Linguistic Inquiry 8, 425-504, 1977.

COSTA, J.; CABRAL, A. C.; SANTIAGO, A.; VIEGAS, F. Conhecimento explícito da língua: guião de implementação do programa. Lisboa: Ministério da Educação, 2011.

DUARTE, I. Conhecimento da língua: Desenvolver a consciência linguística. Lisboa: Ministério da Educação/Direção-Geral de Inovação e de Desenvolvimento Curricular, 2008.

DUARTE, M. E. A perda do princípio "evite pronome" no português brasileiro. 149 f. Tese (Doutorado) - Instituto de Estudos da Linguagem, Universidade Estadual de Campinas, 1995.

GALVES, C. Tópicos, pronomes e concordância no português brasileiro. Cadernos de Estudos Linguísticos, Campinas, v. 34, p. 19-32, jan./jun. 1998.

HOCHSPRUNG, V.; ZENDRON DA CUNHA, K. Que gramática se ensina na escola? Uma análise das classes de palavras em livros didáticos. Miguilim - Revista Eletrônica do Netlli, v. 8, n. 2, p. 589-603, 2019.

HONDA, M.; O’NEIL, W.; PIPPIN, D. On promoting linguistics literacy: Bringing language science into the linguistics classroom. In: DENHAM; LOBECK (Eds.). Linguistics at school: language awareness in Primary and Secondary Education. Oxford University, 2010. p. $175-188$.

KATO, M. A. No mundo da escrita: uma perspectiva psicolinguística. São Paulo: Ática, 1986. 
KATO, M. A.; DUARTE, M. E. L. Restrições na distribuição de sujeitos nulos no Português Brasileiro. Veredas, [S.1.], v.18, n.1, p. 1-22, 2014.

KATO, Mary A.; DUARTE, M. E. L. O Sujeito no Português Brasileiro e sua Tipologia. In: PILATI, E.; SALLES, H. L.; NAVES, R. (Orgs.). Novos olhares para a gramática do português brasileiro. Campinas: Pontes, 2017. p. 13-42.

LAJOLO, M. Livro didático: um (quase) manual de usuário. Em Aberto, Brasília, v.16, n.69, jan./mar., 1996.

LARSON, R. K. Grammar as science. Cambridge: MIT, 2010.

LOBATO, L. M. P. Linguística e ensino de línguas. Brasília: UnB, 2015.

LUNGUINHO, M. V.; MEDEIROS JUNIOR, P. Inventou um novo tipo de sujeito: características sintáticas e semânticas de uma estratégia de indeterminação do sujeito no português brasileiro. Revista de Estudos em Língua e Literatura, 23, p. 147-91, 2009.

MARCHETTI, Greta; et al. Para Viver Juntos - Português: manual do professor. 4. ed. São Paulo: SM, 2015.

NEGRÃO, E.; VIOTTI, E. Estratégias de impessoalização no português brasileiro. In:

FIORIN, J. L.; PETTER, M. (Orgs.). África no Brasil: a formação da língua portuguesa. São Paulo: Contexto, 2008. p. $179-203$.

NEGRÃO, E.; VIOTTI, E. A estrutura sintática das sentenças absolutas no Português Brasileiro. Revista LinguíStica, Rio de Janeiro, v. 23, p. 37-58, 2010.

PERINI, M. A. Gramática descritiva do português. São Paulo: Ática, 1995.

PERINI, M. A. Gramática do português brasileiro. São Paulo: Parábola, 2010.

PIRES DE OLIVEIRA, R.; BASSO, R.; QUAREZEMIN, S. Construindo gramáticas na escola. Florianópolis: UFSC/CCE/DLLE, 2013.

PIRES DE OLIVEIRA, R.; QUAREZEMIN, S. Gramáticas na escola. Petrópolis: Vozes, 2016.

QUAREZEMIN, S. A arquitetura da sentença no português brasileiro: considerações sobre sujeito e tópico. Revista Letras, Paraná, v. 96, p. 196-218, jul./dez. 2017a.

QUAREZEMIN, S. Ensinar linguística na escola: um confronto com a realidade. Working Papers em Linguística. v. 18, n. 2, p. 69-92, 2017 b.

RAPOSO, E. P. A língua como sistema de representação mental. In: Teoria da gramática: a faculdade da linguagem. Lisboa: Caminho, 1992, p.25-63.

REIS, L. M; QUAREZEMIN, S. Posição SUBJP: o caso dos sujeitos locativos no português brasileiro. Revista LinguíStica, vol. 15, n. 3, 2019. p. 69-87. 
RIZZI, L. Issues in Italian Syntax. Dordrecht: Foris, 1982.

SANTOS, E. C. da S. O papel do input no aprendizado do uso do sujeito nulo na escrita por alunos da educação básica. 178 f. Dissertação (Mestrado) - Instituto de Letras, Departamento de Linguística, Português e Línguas Clássicas, Universidade de Brasília, 2013.

XAVIER, L. G. Ensino da gramática: reflexões em torno do verbo. EXEDRA Revista Científica da Escola Superior de Educação de Coimbra, 1, p. 167-176, 2009.

XAVIER, L. G. Ensinar gramática pela abordagem ativa de descoberta. EXEDRA Revista Científica da Escola Superior de Educação de Coimbra, volume temático Português: Investigação e Ensino, p. 467-478, 2012. 